\title{
Correction to: Fed-batch acetone-butanol-ethanol fermentation using immobilized Clostridium acetobutylicum in calcium alginate beads
}

\author{
Russel Navarro Menchavez ${ }^{*}$ and Sung $\mathrm{Ho} \mathrm{Ha}^{* *, \dagger}$ \\ *Department of Biological Engineering, Inha University, Incheon 22212, Korea \\ **Department of Advanced Materials \& Chemical Engineering, Hannam University, Daejeon 34054, Korea \\ (Received 17 December 2018 • accepted 17 January 2019)
}

The article Fed-batch acetone-butanol-ethanol fermentation using immobilized Clostridium acetobutylicum in calcium alginate beads, written by Russel Navarro Menchavez* and Sung Ho $\mathrm{Ha}^{* *, \dagger}$, was originally published on the publisher's internet portal (currently
SPringerLink) on 19 February 2019 with misprinted DOI number, 10.1007/s11814-018-0232-z, due to the technical error from converting manuscript file from Microsoft Word to PDF. The correct DOI number for the article is 10.1007/s11814-019-0317-8.

\footnotetext{
${ }^{\dagger}$ To whom correspondence should be addressed.

E-mail: shha@hannam.kr

Copyright by The Korean Institute of Chemical Engineers.
} 